Please cite this article as:

Heyvaert, M., Maes, B., \& Onghena, P. (2013). Mixed methods research synthesis:

Definition, framework, and potential. Quality \& Quantity, 47, 659-676. doi:10.1007/s11135011-9538-6 
Mixed methods research synthesis:

Definition, framework, and potential.

M. Heyvaert ${ }^{1,2}$, B. Maes $^{3} \&$ P. Onghena ${ }^{2}$

${ }^{1} \mathrm{Ph}$. D. Fellow of the Research Foundation Flanders (FWO)

${ }^{2}$ Methodology of Educational Sciences Research Group, Faculty of Psychology and Educational Sciences, Katholieke Universiteit Leuven, Belgium

${ }^{3}$ Parenting and Special Education Research Group, Faculty of Psychology and Educational Sciences, Katholieke Universiteit Leuven, Belgium

Correspondence concerning this article can be addressed to Mieke Heyvaert, K.U.Leuven, Faculty of Psychology and Educational Sciences, Methodology of Educational Sciences Research Group, Andreas Vesaliusstraat 2, P.O.BOX 3762, B-3000 Leuven, Belgium. E-mail: Mieke.Heyvaert@ped.kuleuven.be. Fax: +32 (0)16 325934. Phone: +32 (0)16 326265. 


\title{
Mixed methods research synthesis: Definition, framework, and potential
}

\begin{abstract}
Literature on the combination of qualitative and quantitative research components at the primary empirical study level has recently accumulated exponentially. However, this combination is only rarely discussed and applied at the research synthesis level. The purpose of this paper is to explore the possible contribution of mixed methods research to the integration of qualitative and quantitative research at the synthesis level. In order to contribute to the methodology and utilization of mixed methods at the synthesis level, we present a framework to perform mixed methods research syntheses (MMRS). The presented classification framework can help to inform researchers intending to carry out MMRS, and to provide ideas for conceptualizing and developing those syntheses. We illustrate the use of this framework by applying it to the planning of MMRS on effectiveness studies concerning interventions for challenging behavior in persons with intellectual disabilities, presenting two hypothetical examples. Finally, we discuss possible strengths of MMRS and note some remaining challenges concerning the implementation of these syntheses.
\end{abstract}

Key words: mixed methods research; mixed methodology; systematic review; research synthesis; intellectual disability; challenging behavior

Mixed methods research, the research paradigm that encourages the combined use of qualitative and quantitative research elements to answer complex questions, is recently gaining enormous popularity (Creswell 2003; Greene 2007; Johnson and Onwuegbuzie 2004; Onwuegbuzie and Leech 2005; Tashakkori and Creswell 2007; Tashakkori and Teddlie 2003b). Mixed methods research can be applied at the primary empirical study level as well as at the synthesis level. In a primary level mixed methods study a researcher collects qualitative and quantitative data directly from the research participants, for example through interviews, observations, and questionnaires, and combines these diverse data in a single study. A synthesis level mixed methods study is a systematic review that applies the principles of mixed methods research. We refer to this type of systematic review by the notion 'mixed methods research synthesis' (MMRS). In such a synthesis, the data to be included in the review are findings extracted from several published qualitative, quantitative, and mixed 
primary level articles. A mixed methods approach combining qualitative and quantitative research elements is used to integrate these qualitative and quantitative research findings within a single systematic review.

Literature concerning mixed methods research at the primary level has accumulated exponentially (Hanson 2008; Leech and Onwuegbuzie 2009). In comparison, very little attention is paid to the possibilities of mixing qualitative and quantitative methods at the synthesis level, although we could expect that the synthesis of qualitative and quantitative research elements could lead to a more integrated and differentiated understanding and insight at this level as well (Creswell and Tashakkori 2007b; Dellinger and Leech 2007; Harden and Thomas 2005, 2010; Hart et al. 2009; Sandelowski et al. 2006; Voils et al. 2008).

Accordingly, over the last two decades several authors have proposed typologies for designing mixed methods designs at the primary level (Creswell et al. 2003; Creswell and Plano Clark 2007; Tashakkori and Teddlie 2003a). The motives behind the articulation of these typologies are diverse, and include (1) presenting a flexible organizational structure for mixed methods research, (2) developing conceptual frameworks that inform and guide the practice of mixed methods inquiry, (3) offering credibility to the mixed methods field by providing successful examples, (4) providing a common language for this field, and (5) facilitating and enhancing the instruction of courses in mixed methods research (Collins and O'Cathain 2009; Greene et al. 1989; Leech and Onwuegbuzie 2009; Teddlie and Tashakkori 2006). These arguments for articulating mixed methods typologies are likewise applicable to the primary- as to the synthesis level. However, to date there exists no such typology framework for the synthesis level. As will be argued in this paper, there are some fundamental differences between mixed methods studies at the primary- and synthesis level, and it would not suffice to simply appeal to existing typologies for mixed methods studies at the primary level when designing an MMRS. In order to fill this gap, this paper develops and introduces a typology framework for MMRS.

Since the intent of this paper is to explore the possible contribution of mixed methods research to the integration of qualitative and quantitative research at the synthesis level, we start by defining mixed methods research at the synthesis level. Second, the framework to 
carry out an MMRS is presented. Third, this framework is illustrated by applying it to the planning of MMRS on effectiveness studies concerning interventions for challenging behavior in persons with intellectual disabilities (ID). Two hypothetical examples are presented. Fourth, we discuss possible strengths of MMRS and note some remaining challenges concerning the implementation of these syntheses.

\section{Mixed methods research at the synthesis level}

\section{Synthesizing research evidence}

During the last decades, the need to synthesize research evidence in order to inform policy makers, practitioners, and fellow scientists concerning the most recent developments on a certain topic has been recognized (Chalmers et al. 2002; Mays et al. 2005). Especially due to the Evidence-Based Practice Movement (EBP), systematic reviews are nowadays highly valued as they often form the basis for evidence-based clinical practice guidelines. As a result, several methods and techniques to systematically aggregate evidence have been (further) developed. Various terms (e.g., systematic review, integrative review, research synthesis, realist synthesis, qualitative review, narrative review, meta-analysis) are used to describe different variants of the methods and techniques developed to synthesize empirical evidence (Forbes and Griffiths 2002; Major and Savin-Baden 2010; Pluye et al. 2009; Suri and Clarke 2009; Whittemore and Knafl 2005; Zimmer 2006).

Historically, two major approaches of research synthesis have been applied. First, a variety of qualitative synthesis methods - 'systematic review', 'narrative review', 'meta-study', 'metasynthesis', 'meta-summary', 'meta-ethnography', 'grounded formal theory', 'aggregated analysis' - is used to generate new insights and understanding from interrelated qualitative research findings. Second, several statistical models and techniques (e.g., fixed and random effects models, and varying techniques to address heterogeneity and bias) are applied to conduct meta-analyses of quantitative research evidence. In addition to these two approaches, recently some pioneering work has been done concerning the mixed synthesis of various types of qualitative, quantitative, and mixed primary level research evidence (Harden and Thomas 2005, 2010; Pluye et al. 2009; Sandelowski et al. 2006; Voils et al. 2008). 
As depicted in the left rectangle of Figure 1, qualitative methods for research synthesis are applied to bring together data collected, analyzed and interpreted in qualitative, and sometimes also in quantitative and mixed primary level studies (Jensen and Allen 1996; Johnson and Onwuegbuzie 2004; Mays et al. 2001; Paterson et al. 2001; Rice 2008; Sandelowski et al. 1997; Walsh and Downe 2005). As shown in the middle rectangle of Figure 1, a quantitative synthesis particularly includes data from quantitative primary level studies (Cooper 1998; Hampton 2002; McKenna et al. 1999; Mitchell 1999), although sometimes data from qualitative studies are transformed to be incorporated in these syntheses as well (Johnson and Onwuegbuzie 2004; Sandelowski et al. 2009). In addition, quantitative data (or data fragments) investigated in primary level mixed studies can be included in a quantitative synthesis. As can be seen in the right rectangle of Figure 1, a mixed methods research synthesis can investigate data coming from qualitative, quantitative, and mixed primary level studies (Harden and Thomas 2005, 2010; Sandelowski et al. 2006; Voils et al. 2008). 
Primary level studies

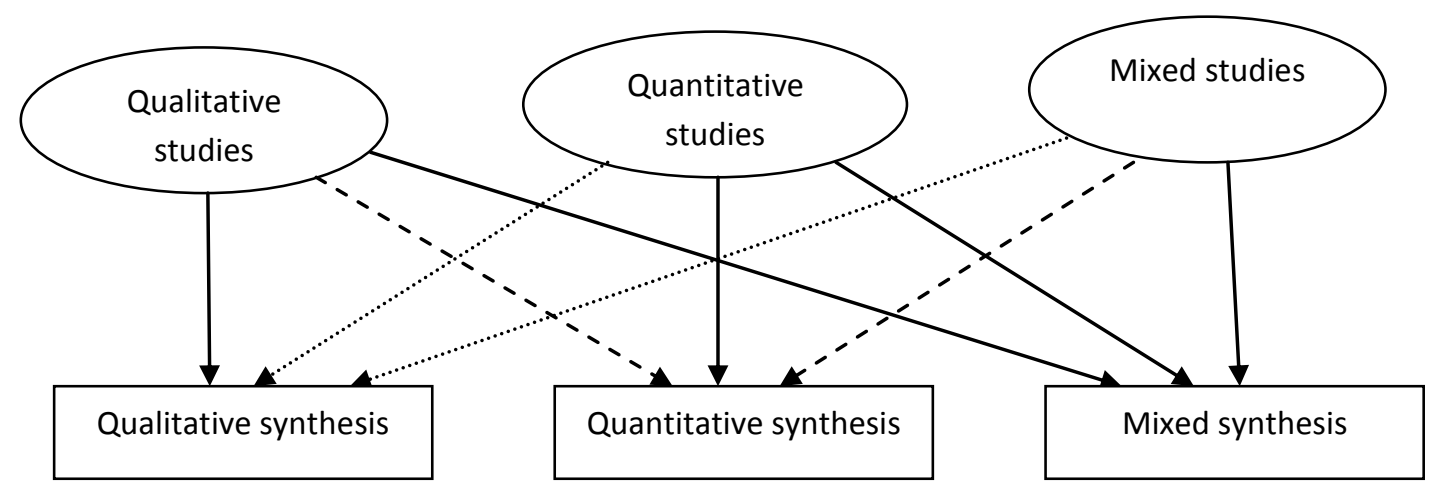

Note: Notational system for the arrows:

$\longrightarrow$ 'this type of primary level studies (circle) is often combined in this type of synthesis (rectangle)'

'this type of primary level studies (circle) is sometimes combined in this type of synthesis (rectangle)

_. - ' this type of primary level studies (circle) is only rarely combined in this type of synthesis (rectangle)'

Figure 1. Qualitative, quantitative, and mixed methods research synthesis

\section{Defining mixed methods research at the synthesis level}

A mixed methods research synthesis is a systematic review applying the principles of mixed methods research. As discussed by Creswell and Tashakkori (2007a), the latter implies that the study is not only expected to have two well-developed distinct strands, one qualitative and one quantitative, each complete with its own questions, data, analysis, and inferences, it must also integrate, link, or connect these strands in some way (see Bryman 2007). It is a systematic review, which means that it reviews available research data that has been systematically searched for, studied, assessed, and summarized according to predetermined, transparent, and rigorous criteria. In an MMRS the data that are integrated in the review are findings extracted from qualitative, quantitative, and mixed primary level articles. So, where in a primary level study the participants are people, in a synthesis level study the participants are primary level studies. Following the general definition of mixed methods research proposed by Johnson et al. (2007), we define an MMRS as a synthesis in which researchers combine qualitative, quantitative, and mixed methods studies, and apply a mixed methods approach in order to integrate those studies, for the broad purposes of breadth and depth of understanding and corroboration. 
Other suggestions concerning terminology for this synthesizing of qualitative and quantitative primary level studies are 'mixed research synthesis' (Sandelowski et al. 2006; Voils et al. 2008), 'mixed studies review' (Pluye et al. 2009), and 'mixed methods synthesis' (Harden and Thomas 2005).

Supported by the work of other authors (Harden and Thomas 2005, 2010; Hart et al. 2009; Sandelowski et al. 2006), we believe that the integration of qualitative and quantitative studies at the synthesis level has promising utility for research and practice, since the rationale for conducting mixed methods synthesis research lies in combining the strengths of qualitative and quantitative techniques and studies, which are jointly available in many domains of research (Pluye et al. 2009; Sandelowski et al. 2006).

\section{A framework for MMRS}

\section{A classification framework for MMRS}

Our framework for MMRS was developed through a stepwise process. First, we studied existing classifications for mixed methods designs at the primary level. We found that the designs described by Creswell (2003), Creswell and Plano Clark (2007), Greene et al. (1989), Johnson and Onwuegbuzie (2004), Leech and Onwuegbuzie (2009), Mertens (2005), Morgan (1998), Morse (1991), and Tashakkori and Teddlie (1998) (rows in Table 1) are often referred to by other mixed methods authors, and are often mentioned in mixed methods studies (for example, see Andrew and Halcomb 2006; Bazeley 2004; Bryman 2006; Collins and O’Cathain 2009; Doyle et al. 2009).

Second, we explored the dimensions on which their frameworks are based. An analysis of these influential typologies showed that mixed methods designs are usually classified according to some of the following five dimensions: emphasis of approaches, temporal orientation, integration, purpose of the study, and theoretical framework of the study (columns in Table 1). The cells of Table 1 indicate which design types the above named researchers (row heads) differentiate within these five dimensions (column heads). 
Table 1. Classification frameworks for mixed methods designs at the primary level

\begin{tabular}{|c|c|c|c|c|c|}
\hline & $\begin{array}{l}\text { Emphasis of } \\
\text { approaches }\end{array}$ & $\begin{array}{l}\text { Temporal } \\
\text { orientation }\end{array}$ & Integration & $\begin{array}{l}\text { Purpose of the } \\
\text { study }\end{array}$ & $\begin{array}{l}\text { Theoretical } \\
\text { framework of } \\
\text { the study }\end{array}$ \\
\hline Creswell 2003 & $\begin{array}{l}\text { QUAL dominant } \\
\text { QUAN dominant } \\
\text { Embedded design }\end{array}$ & $\begin{array}{l}\text { Concurrent } \\
\text { Sequential }\end{array}$ & $\begin{array}{l}\text { Stage of } \\
\text { integration }\end{array}$ & Triangulation & Transformative \\
\hline $\begin{array}{l}\text { Creswell and } \\
\text { Plano Clark } \\
2007\end{array}$ & Embedded design & & & $\begin{array}{l}\text { Triangulation } \\
\text { Explanatory } \\
\text { Exploratory }\end{array}$ & \\
\hline $\begin{array}{l}\text { Greene et al. } \\
1989\end{array}$ & & & & $\begin{array}{l}\text { Triangulation } \\
\text { Complementary } \\
\text { Development } \\
\text { Initiation } \\
\text { Expansion }\end{array}$ & \\
\hline $\begin{array}{l}\text { Johnson and } \\
\text { Onwuegbuzie } \\
2004 \\
\end{array}$ & $\begin{array}{l}\text { Equal status } \\
\text { Dominant status }\end{array}$ & $\begin{array}{l}\text { Concurrent } \\
\text { Sequential }\end{array}$ & & & \\
\hline $\begin{array}{l}\text { Leech and } \\
\text { Onwuegbuzie } \\
2009\end{array}$ & $\begin{array}{l}\text { Equal status } \\
\text { Dominant status }\end{array}$ & $\begin{array}{l}\text { Concurrent } \\
\text { Sequential }\end{array}$ & $\begin{array}{l}\text { Partially mixed } \\
\text { Fully mixed }\end{array}$ & & \\
\hline Mertens 2005 & & $\begin{array}{l}\text { Parallel } \\
\text { Sequential }\end{array}$ & & & $\begin{array}{l}\text { Pragmatic } \\
\text { Transformative }\end{array}$ \\
\hline Morgan 1998 & $\begin{array}{l}\text { QUAL dominant } \\
\text { QUAN dominant }\end{array}$ & $\begin{array}{l}\text { Complementary } \\
\text { method preliminary } \\
\text { or follow-up }\end{array}$ & & & \\
\hline Morse 1991 & $\begin{array}{l}\text { QUAL dominant } \\
\text { QUAN dominant }\end{array}$ & $\begin{array}{l}\text { Simultaneous } \\
\text { Sequential }\end{array}$ & & & \\
\hline $\begin{array}{l}\text { Tashakkori and } \\
\text { Teddlie } 1998\end{array}$ & $\begin{array}{l}\text { Equal status } \\
\text { Dominant status }\end{array}$ & $\begin{array}{l}\text { Parallel } \\
\text { Sequential }\end{array}$ & $\begin{array}{l}\text { Multilevel use } \\
\text { of approaches }\end{array}$ & & \\
\hline
\end{tabular}

The third step included questioning which dimensions that had been identified in mixed methods studies at the primary level are relevant for distinguishing mixed methods designs at the synthesis level. Because it is plausible that not all the dimensions identified at the primary level are equally relevant at the synthesis level, we carefully compared several primary level and synthesis level mixed methods studies and their designs. The development of our classification framework was guided by three questions: (1) Which design-distinguishing dimensions found at the primary level are particularly relevant at the synthesis level? (2) Which design-distinguishing dimensions found at the primary level are less relevant at the synthesis level? (3) Which differences exist between mixed methods studies at the primary and synthesis level?

(1) Which design-distinguishing dimensions found at the primary level are particularly relevant at the synthesis level?

'Emphasis of approaches' and 'Temporal orientation' are dimensions that are often applied to distinguish mixed methods designs at the primary level (see Table 1). We believe that both dimensions are key to distinguish between mixed methods designs at the synthesis level as well. We add a third dimension that especially distinguishes our framework for designing 
mixed methods studies at the synthesis level from frameworks concerning the primary-study level: the 'Integration'. We will briefly describe what these dimensions stand for.

First, the dimension 'Emphasis of approaches' indicates whether a qualitative or quantitative approach has the priority with regard to the study's purpose and its research questions, the data collection and analysis, and the interpretation of the findings, or whether both approaches have an approximate equal weight and influence.

Second, the dimension 'Temporal orientation' indicates whether qualitative and quantitative research phases or sub-phases occur simultaneously or sequentially. In a simultaneous design the qualitative and quantitative data are collected concurrently, and parallel analyzed in a complementary manner. When both methods are implemented simultaneously and interactively within a single study, the interpretability of the results can be enhanced (Greene et al. 1989). On the contrary, in a sequential design the quantitative and qualitative research phases are conducted separately. The results of the method first implemented can help to identify and refine the review question and/or the relevant outcomes of interest, to select the data, to develop a theory or hypothesis, or to inform the analysis of the other method (DixonWoods et al. 2001; Greene et al. 1989). The two-phase design is the most elementary sequential design. However, the sequencing quantitative and qualitative phases can go through several cycles within a single study as well.

A third dimension that appears to be of major importance when combining qualitative, quantitative, and mixed primary level studies in an MMRS, is 'Integration'. The retrieved qualitative and quantitative data might be integrated at several stages in the research process: at the data collection, the data analysis, the interpretation phase, or a combination of phases (Creswell 2003). Morse and Niehaus (2009) define the position in which the qualitative and quantitative components meet during the conduct of the research as the point of interface. The dimension 'Integration' particularly distinguishes this framework for designing mixed methods studies at the synthesis level from frameworks concerning the primary study level. As will be further explained in (3), a researcher engaging in an MMRS is limited in his choices to design the synthesis due to the number of primary level studies including qualitative, quantitative, or mixed data that are available on a certain research topic. At the synthesis level, the dimension 'Integration' indicates the difference between a synthesis that involves all the retrieved qualitative and quantitative articles in all the analyses and stages, and a synthesis that analyzes (parts of) the retrieved qualitative and quantitative articles separately. The former approach can for example be applied to examine the degree of accordance between qualitative and quantitative elements found in the same group of studies, 
in order to corroborate results or identify discrepancies within this group of studies. For example, a certain treatment for challenging behavior in persons with ID may result in high effect scores (quantitative data), while the family of these persons report several negative side effects of this treatment (qualitative data), or experience a contextual misfit of the treatment. Here, mixed methods could be used to identify discrepancies within a group of treatment studies by comparing qualitative and quantitative 'experience' and 'effect' data concerning the applied treatments. The latter approach for example applies when the synthesis is conducted separately on the qualitative and quantitative studies before being combined in the results and conclusion section. This approach can be used to expand or explain findings based on several primary level articles by another set of articles (e.g., a set of deviant case articles in confrontation with a set of contextual background articles and a set of national surveys). In addition, it is also possible that primary level mixed articles are included in the review, each containing qualitative and quantitative data. In that case, the qualitative and quantitative data reported in those articles can be included in the qualitative and quantitative analysis respectively (cfr. 'parts of').

(2) Which design-distinguishing dimensions found at the primary level are less relevant at the synthesis level?

The dimensions 'Purpose of the study' and 'Theoretical framework' do not warrant a separate place in our framework. Although it is at the utmost importance for a researcher to reflect on the objective of the study at hand, the dimension 'Purpose of the study' is not included in our framework since differences between 'triangulation', 'explanatory' and 'exploratory' designs (see Table 1) can be translated into differences between equal versus dominant status of, and simultaneous versus sequential use of qualitative and quantitative approaches (Creswell et al. 2003; Creswell and Plano Clark 2007; Greene et al. 1989), two dimensions that are already incorporated in our framework. On the other hand, when considering the functions of a mixed methods study described by Greene et al. (1989), the decision whether to select a complementary-, development-, initiation- or expansion-function for your MMRS depends on the number of retrieved primary level studies including qualitative, quantitative, or mixed data (see: (3)), and can be related to the dimension 'Integration'.

The dimension 'Theoretical framework' often distinguishes between 'pragmatic' and 'transformative-emancipatory' mixed methods designs (Creswell 2003; Greene and Caracelli 1997; Mertens 2005). However, the majority of mixed methods studies have pragmatism as the paradigmatic basis for methodologically combining qualitative and quantitative 
approaches (Feilzer 2010; Johnson and Onwuegbuzie 2004; Morgan 2007; Tashakkori and Creswell 2007). When an individual researcher applies an alternative theoretical framework (e.g., transformative-emancipatory perspective, dialectical worldview, communities of practice) it is desirable to make this explicit (Denscombe 2008; Mertens 2007, 2010; Plano Clark et al. 2008).

\section{(3) Which differences exist between mixed methods studies at the primary-and synthesis} level?

We found one major difference between published mixed methods studies at the synthesisand primary level: the 'range of choices' of the researcher to design the study. A researcher conducting a primary level mixed study chooses which qualitative and quantitative data he collects in order to answer the research question(s), and with which qualitative and quantitative methods he analyzes those data. So, he decides whether qualitative or quantitative (or both) data and methods are dominant in the study.

However, a person conducting an MMRS can only work with the available primary level studies on the research topic, containing a certain amount of reported qualitative and quantitative data material. Although he can for example decide which inclusion and exclusion criteria are used to select the primary level studies, and with which qualitative and quantitative methods he analyzes those data, he still is strongly limited by the kind and amount of qualitative and quantitative information reported in the available primary level studies in the chosen research domain. As a consequence, at the synthesis level the choice for an MMRS design not only depends on the posed research question, but also on the available qualitative and quantitative information that is reported in the primary level articles.

This 'range of choices' for a researcher to design a mixed methods synthesis study is not included as a fourth dimension in our classification framework, since it applies to all MMRS, and only presents a difference between published mixed methods studies at the synthesisversus primary level.

Summarizing, from the five dimensions that are often applied to distinguish mixed methods designs at the primary level (see Table 1), especially the dimensions 'Emphasis of approaches', 'Temporal orientation', and 'Integration' are relevant at the synthesis level. A matrix derived by combining these three dimensions (presented as column heads in Table 2) yields 18 types of MMRS (indicated in bold and italics in Table 2). Guided by his research 
question, and by the amount of available qualitative and quantitative data that are reported in primary level studies, a researcher may choose one of these 18 designs.

Table 2. A classification framework for MMRS

\begin{tabular}{|c|c|c|c|}
\hline \multirow{2}{*}{$\begin{array}{l}\text { Emphasis of } \\
\text { approaches }\end{array}$} & \multirow[b]{2}{*}{ Integration (a) } & \multicolumn{2}{|l|}{ Temporal orientation } \\
\hline & & $\begin{array}{l}\text { Concurrent Qual and Quan } \\
\text { approach }\end{array}$ & $\begin{array}{l}\text { Sequential Qual and Quan } \\
\text { approach }\end{array}$ \\
\hline \multirow{4}{*}{$\begin{array}{l}\text { Equal status of } \\
\text { qualitative and } \\
\text { quantitative } \\
\text { approaches }\end{array}$} & \multirow{2}{*}{$\begin{array}{l}\text { All Qual and Quan data involved } \\
\text { in all research stages }\end{array}$} & \multirow[t]{2}{*}{$A-Q U A L+Q U A N(1)$} & $A-Q U A L \rightarrow Q U A N(3)$ \\
\hline & & & $A-Q U A N \rightarrow Q U A L(4)$ \\
\hline & \multirow{2}{*}{$\begin{array}{l}\text { (Parts of) Qual and Quan data } \\
\text { involved separately in some/all } \\
\text { research stages }\end{array}$} & \multirow[t]{2}{*}{$S-Q U A L+Q U A N(2)$} & $S-Q U A L \rightarrow Q U A N(5)$ \\
\hline & & & $S-Q U A N \rightarrow Q U A L(6)$ \\
\hline \multirow{8}{*}{$\begin{array}{l}\text { Dominant status } \\
\text { of qualitative or } \\
\text { quantitative } \\
\text { approaches }\end{array}$} & \multirow{4}{*}{$\begin{array}{l}\text { All Qual and Quan data involved } \\
\text { in all research stages }\end{array}$} & \multirow{2}{*}{$A-Q U A L+q u a n(7)$} & $A-Q U A L \rightarrow$ quan $(11)$ \\
\hline & & & $A-q u a n \rightarrow Q U A L(12)$ \\
\hline & & \multirow{2}{*}{$A-Q U A N+q u a l(8)$} & $A-Q U A N \rightarrow q u a l(13)$ \\
\hline & & & $A-q u a l \rightarrow Q U A N(14)$ \\
\hline & \multirow{4}{*}{$\begin{array}{l}\text { (Parts of) Qual and Quan data } \\
\text { involved separately in some/all } \\
\text { research stages }\end{array}$} & \multirow{2}{*}{$S-Q U A L+q u a n(9)$} & $S-Q U A L \rightarrow$ quan (15) \\
\hline & & & $S-$ quan $\rightarrow Q U A L(16)$ \\
\hline & & \multirow{2}{*}{$S-Q U A N+q u a l(10)$} & $S-Q U A N \rightarrow$ qual (17) \\
\hline & & & $S$ - qual $\rightarrow Q U A N(18)$ \\
\hline
\end{tabular}

Notations: the plus sign (+) indicates that the qualitative and quantitative approaches are conducted simultaneously; the arrow $(\rightarrow)$ indicates that the qualitative and quantitative approaches are conducted sequentially; the uppercase indicates the dominant method of synthesis; the lowercase indicates the not-dominant method of synthesis; the A-sign indicates that all the qualitative and quantitative data are involved in all research stages; the S-sign indicates that (parts of) the qualitative and quantitative data are involved separately in some or all research stages

Note (a): As pictured in Figure 1, the qualitative and quantitative data that are incorporated in an MMRS can come from qualitative, quantitative, and mixed primary level articles.

\section{Implementing MMRS}

Frameworks for systematically synthesizing research evidence incorporate the following stages: (1) the problem identification and question formulation stage, (2) the development of a review protocol and the literature search, (3) the selection of an appropriate design and method, (4) the data extraction and evaluation stage, (5) the data analysis and interpretation stage, and (6) the reporting and discussing of research findings (Cooper 1998; Cooper and Hedges 1994; Furlan et al. 2009; Gelo et al. 2008; Khan et al. 2001; Major and Savin-Baden 2010; Onwuegbuzie and Leech 2005; Oxman and Guyatt 1988; Whittemore and Knafl 2005). We will present a general elaboration of each of these stages involved in doing an MMRS by giving two hypothetical illustrations of the classification framework in the domain of effectiveness studies concerning interventions for challenging behavior in persons with ID. 


\section{Illustrations of the classification framework}

\section{Illustration of MMRS about the effect of interventions for challenging behavior in people with intellectual disabilities}

Challenging behaviors are culturally abnormal behavior of such an intensity, frequency or duration that the physical safety of the person or others is likely to be placed in serious jeopardy, or behavior which is likely to seriously limit use of, or results in the person being denied access to, ordinary community facilities (Emerson 1995). Since challenging behaviors are highly prevalent among persons with ID and generate negative consequences for the individual and his/her family, divergent biological, psychological, behavioral, and contextual interventions are developed to reduce these behaviors (Antonacci et al. 2008; Bouras 1999; Didden et al. 1997; Dösen and Day 2001; Grey and Hastings 2005; Matson and Neal 2009; McGillivray and McCabe 2006).

There exist several quantitative and qualitative reviews on the effects of different interventions for challenging behavior in people with ID (Balogh et al. 2008; Brylewski and Duggan 1999; Chan et al. 2010; Deb et al. 2007, 2008; Didden et al. 1997, 2006; Gustafsson et al. 2009; Harvey et al. 2009; Heyvaert et al. 2010; Lang et al. 2010; Shogren et al. 2004; Sohanpal et al. 2007), while MMRS are not available for the time being. We believe that MMRS could contribute to the development of this research domain by the integration of and confrontation between the many empirical qualitative and quantitative studies that are available. Thereby, MMRS could answer a broader and more complete range of research questions, and add insights and understanding that might be missed when only a single method is used (Johnson and Onwuegbuezie 2004).

In our classification framework, 18 designs have been distinguished. We will illustrate the distinction between these designs by describing two 'extreme' cells, namely cell 1 (A - QUAL + QUAN) and cell 18 (S - qual $\rightarrow$ QUAN), pictured as the left above and right bottom design in Table 2. As such, we present two diverging hypothetical applications of MMRS. Elaborations of the other cells of Table 2 can be deduced from these two examples. For both cells, we will hypothetically work out a synthesis on the effects of different interventions for challenging behavior in persons with ID, through the six above-described research stages. 


\section{Hypothetical application 1}

First of all, we should clearly identify the problem that the review is addressing, and the review purpose (Maxwell 2005; Onwuegbuzie and Leech 2005; Whittemore and Knafl 2005). Let 's suppose that we work for a governmental service that studies treatments for challenging behavior in persons with ID in order to give advice to centers and institutions working with these persons. Our problem could be that we have, based on reading on this topic, the presumption that although some high effect scores (quantitative data) favorable to a certain treatment for challenging behavior in persons with ID (called treatment X) are published, this treatment should not be implemented on a large scale in his current form, since we heard several negative reactions to treatment $\mathrm{X}$ from staff claiming that this treatment only produces good outcomes under very specific conditions. Our aim could be to systematically review all the available primary level studies on treatment $\mathrm{X}$ for this target group, in order to thoroughly answer the question 'what is it about this intervention that works (and does not work), for whom, in what circumstances, in what respects, and why?' (see also Pawson et al. 2005). Since we are not interested in the quantitative effect of treatment $\mathrm{X}$ an sich, but especially in its relation to several 'black box' intervention characteristics and participants features, as well as in features of the context wherein each of the published interventions is embedded, we intend to perform an MMRS.

The second stage involves the development of a review protocol and the literature search. In the review protocol, we describe and justify our search strategy, the selection of inclusion and exclusion criteria, the quality assessment, the data extraction strategy, and the way in which we synthesize the extracted findings (Furlan et al. 2009; Khan et al. 2001; Major and SavinBaden 2010; Oxman and Guyatt 1988; Whittemore and Knafl 2005). We search electronic databases, screen reference lists of retrieved articles, hand search, look for grey literature and conference proceedings, search research registers, and contact individual researchers (Cooper 1998; Cooper and Hedges 1994; Furlan et al. 2009; Khan et al. 2001; Oxman and Guyatt 1988). So, we systematically retrieve primary level studies, and document this search in detail. If we would choose to perform a meta-analysis for the quantitative part of the MMRS, all the selected articles should contain data that make the application of meta-analytic techniques possible. Because we want to study this statistical effect in its relation to several context, participants, and intervention features, the articles that will be included in our review have to contain descriptions of these features as well. 
Third, we should select an appropriate research design, and provide a rationale for its implementation. We would select an 'A - QUAL + QUAN' research design, since we want to study all ('A') the included articles (containing quantitative effect data on treatment $\mathrm{X}$ and qualitative data on context, participants, and intervention features) by equally applying qualitative and quantitative research techniques ('QUAL QUAN') that are 'in an interactive dialogue' ('+') with one another in order to understand and explain the differential effects for treatment $\mathrm{X}$ in persons with ID.

Fourth, as a rule of thumb at least two reviewers should independently extract the articles, documenting their search in detail by using data extraction forms (Furlan et al. 2009; Khan et al. 2001). In addition, these articles should be evaluated with a quality assessment instrument (e.g., the instrument presented in Pluye et al. 2009).

Fifth, the data analysis stage would involve concurrent qualitative and quantitative analyses that are in dialogue with one another. We would record context, participants, and intervention features, and intervention effects for each included article (see Heyvaert et al. 2010). Since we are interested in the relation between the quantitative effect data on treatment $\mathrm{X}$ and several contextual, 'black box' intervention, and participants features, we would stepwise navigate between the qualitative and quantitative information that is available in the published studies, and stepwise analyze this information by qualitative and quantitative techniques. We could start with generating comparable effect size measures for all the included primary level studies and statistically testing the general hypothesis that treatment $\mathrm{X}$ produces positive quantitative outcome effects for challenging behavior in persons with ID by means of a random-effects meta-analysis of all the included studies (Borenstein et al. 2009; Cooper and Hedges 1994; see for example Heyvaert et al. 2010 for a detailed description of a randomeffects meta-analysis on this topic). Concurrently, we could systematically collect all the available qualitative information on intervention, context, and participants features, and meanwhile systematically identify possible relations between the intervention effects on the one hand, and 'black box' intervention, context, and participants features on the other hand. The identified possible relations could be tested by statistical analysis and be afterwards looped back to the qualitative systematic analysis. The qualitative systematic analysis could adjust the former hypotheses or generate new hypotheses based on the results of this statistical analysis. These adjusted or new hypotheses could again be tested by statistical analysis and be looped back to the qualitative systematic analysis, and so on. So, the statistical meta-analytic and qualitative descriptive and analytical results could be stepwise integrated by identifying matches, mismatches, and gaps (see for an example Harden et al. 2004; Oliver et al. 2005). In 
the end, the qualitative and quantitative data should be integrated in answering the question what is it about the reviewed intervention that works (and does not work), for whom, in what circumstances, in what respects, and why. By additionally implementing sequential metaanalytic analyses, the sufficiency of the retrieved cumulative knowledge could be determined and the question could be answered whether there yet exists enough cumulative knowledge on treatment $\mathrm{X}$ implemented under certain conditions to yield conclusive statistical evidence, or whether additional research on this treatment is needed (Kuppens and Onghena, 2010).

Finally, we should describe our methods and results, and the implications for practice, research, and policy in a research report, and communicate our research conclusions to centers and institutions working with persons with ID.

\section{Hypothetical application 2}

Another research problem could be that we intend to perform a meta-analysis of articles on different interventions for challenging behavior among persons with ID, and that we are especially interested in variables moderating the intervention effects, but that we do not know which possible influencing variables (moderators) should be included in our analysis, and how these variables are related to one another. Our proposed review purpose would then be to determine which interventions for challenging behavior among persons with ID produce which effects, moderated by which variables.

Second, the development of a review protocol, the selection of the studies, and the literature search would be identical to the procedure described in Application 1. We could include different (and possibly more) studies in our preceding qualitative analysis than in the dominant statistical meta-analysis, in order to generate a thematic network between the variables involved in the intervention process that is as comprehensive as possible.

Third, we could select an 'S - qual $\rightarrow$ QUAN' research design, because we want to study this topic by implementing a meta-analysis ('QUAN'), but first need to explore which variables should be included in our analysis and how these variables are related, for example through a qualitative thematic analysis sub-study ('qual $\rightarrow$ ') that is based on possibly different primary articles than the articles included in the main meta-analysis (' $\mathrm{S}$ ').

Fourth, parallel to Application 1, at least two reviewers should independently extract primary level articles, and assess the quality of these articles.

Fifth, we could start by conducting a thematic analysis ('qual $\rightarrow$ ') in order to structure and depict all the variables involved in the intervention process. We could prefer thematic analysis 
because our research questions ask for a flexible analysis technique that clearly summarizes key features of a large body of data and still offers a 'thick description' of the data set (Attride-Stirling 2001; Braun and Clarke 2006; Dixon-Woods et al. 2005; Harden and Thomas 2005; Walsh and Downe 2005). The use of visual representations (thematic networks; Attride-Stirling 2001) could assist us in organizing relationships between variables, and between different levels and groups of variables (main variables and sub-variables). We would analyze several primary articles on this topic until a saturation point is reached. The result of this preliminary analysis would consist of a thematic network incorporating all variables connected with this intervention process. Afterwards, we could perform a randomeffects meta-analysis (' $\rightarrow Q U A N$ ') on the effects of various interventions for challenging behavior in people with intellectual disability (see Heyvaert et al. 2010 for a more detailed description of all the suggested meta-analytic procedures on this topic). Effect sizes and variances should be computed for all included studies' intervention effects. We could generate a summary effect with a $95 \%$ confidence interval, and measures of heterogeneity (Q-value, Tau-squared, I-squared). Next to that, we could assess the impact of the possible moderating variables (detected by the preceding thematic analysis) through subgroup and meta-regression analysis. Furthermore, a sensitivity analysis could be performed, each time removing one study, in order to show each study's impact on the combined effect. In addition, we could analyze the possible impact of publication bias by a funnel plot-, a fail-safe N-, and Duval's and Tweedie's trim and fill-analysis. So, we could obtain answers to the question which interventions for challenging behavior among persons with ID generate which effects, moderated by which variables.

In our last research step, we should write the research report, containing a detailed description of our methods and results, and the implications for practice, research, and policy.

\section{Future issues for MMRS}

This paper intended to introduce the fascinating and promising, but still relatively new, domain of MMRS. In addition, we wanted to stimulate a thoughtful designing of MMRS by discussing various dimensions that shape this type of research. That is why we presented a framework to carry out MMRS. By doing this, our manuscript adds to the mixed methods literature through filling a salient gap in the methodology of mixed methods research. After all, although several typologies for mixed methods designs at the primary level have been 
proposed in order to inform and guide the practice of mixed methods inquiry, there existed no such typology framework for the synthesis level. As we argued that the 'range of choices' of the researcher to design the study constitutes a fundamental difference between mixed methods studies designed at the primary- and synthesis level, simply referring to existing primary level typologies for mixed methods designs would not suffice when designing an MMRS. Answering this void, we introduced a framework for designing such MMRS. In addition, the manuscript fills a salient gap in the methodology of research synthesis by introducing the mixed methods perspective. The presented classification framework can help to inform researchers planning to carry out MMRS, and to provide ideas for conceptualizing and developing those syntheses. Note however, that the framework is not intended as a rigid or formulaic labeling for research.

Our framework was illustrated by two hypothetical MMRS applications on effectiveness studies concerning interventions for challenging behavior in persons with ID. In this research domain several authors carry out qualitative syntheses, because there are not so many primary level articles that contain (enough) data to allow statistical meta-analysis. Here, an MMRS could be a good alternative: qualitative as well as quantitative primary level articles could be incorporated in the study. So, the researcher is not forced to exclude any available data from the synthesis. A more varied and possibly more nuanced palette of information on the topic at hand can be included in the analysis.

To conclude, we note several strengths of MMRS concerning the mixing of qualitative and quantitative primary level findings and of qualitative and quantitative synthesis techniques.

First, the main advantage of the mixing of findings from qualitative and quantitative primary level articles is that - compared to 'unmixed' syntheses - more complete, concrete, and nuanced answers can be given to complex research questions. For example, in the MMRS of Thomas et al. (2004) the combining of 'quantitative' controlled-trial articles describing the effects of interventions that promoted healthy eating with 'qualitative' studies that examined the perspectives and understandings of children concerning barriers to and facilitators of fruit and vegetable intake, increases the policy relevance of the review since it can lead to the development of more effective and appropriate interventions (Harden and Thomas 2005). As such, an MMRS can answer multiple aspects of the question 'what is it about this kind of intervention that works, for whom, in what circumstances, in what respects, and why?' (see also Pawson et al. 2005). 
Second, the combination of qualitative and quantitative synthesis approaches holds the possibility to help confirm or refute a theory to a greater degree than either one method can do on its own (Risjord et al. 2002), or to uncover and profoundly explain discrepancies between the findings of the included studies. For example, in the study of Thomas et al. (2004) the insights gained from the qualitative synthesis allowed an in-depth and nuanced exploration of the detected statistical heterogeneity.

Other advantages of mixed methods research are its attempts to fully respect the contribution and wisdom of both the qualitative and quantitative viewpoints, and to seek a workable middle solution for addressing divergent research problems (Johnson et al. 2007; Leech and Onwuegbuzie 2009; Niaz 2008; Tashakkori and Teddlie 2003b). After all, when researchers collect multiple data using different strategies, approaches, and methods in such a way that the resulting mixture or combination is likely to result in complementary strengths and counterbalancing weaknesses, a mixed methods study has the potential to produce a more robust understanding of a complex phenomenon, which is unavailable in a qualitative or a quantitative study undertaken in isolation (Gelo et al. 2008; Greene et al. 1989; Johnson and Onwuegbuzie 2004; Morgan 1998; O'Cathain et al. 2007; Onwuegbuzie and Johnson 2006; Plano Clark et al. 2008; Robins et al. 2008).

However, there remain several challenges concerning the implementation of an MMRS. First of all, although most researchers agree that the quality-quantity dichotomy and the 'incommensurability'-position is restricted, sterile, or even misleading (Morgan 2007; Newman and Benz 1998; Niglas 2006), various paradigmatic assumptions are still being debated when conceptualizing, implementing, and interpreting mixed methods studies (Greene 2008; Jang et al. 2008; Mertens 2010). Combining quantitative and qualitative studies and methods with traditionally different viewpoints concerning ontology (single vs. multiple reality), epistemology (objectivism vs. subjectivism), and axiology (value bound vs. value free) can turn out quite challenging (Bryman 2007; Johnson et al. 2007; Onwuegbuzie and Johnson 2006).

Second, there exist several methodological pitfalls generated by the diversity between and within the mixed qualitative and quantitative methods (Greene 2006). After all, MMRS not only imply the integration of divergent qualitative and divergent quantitative studies within separate qualitative and quantitative strands of a synthesis, they most importantly involve the 
integration of the conclusions from the qualitative and quantitative strands (for example in the form of comparing, contrasting, building on, or embedding one type of conclusion with the other) in order to provide a fuller understanding of the phenomenon under study (Creswell and Tashakkori 2007a).

Third, answers to the questions whether it makes sense to perform an MMRS on a certain topic, and which primary level studies can be combined within a single synthesis, depend on the research domain and the topic at hand, the goal(s) of the synthesis, and the posed research question(s). Remembering Eysenck's (1978) comments on combining apples and oranges, we have to annotate that a synthesis only gains credibility when the data in the included primary articles are comparable enough to be combined to answer a single research question. Although this comment counts for MMRS as much as for meta-analyses and qualitative metasyntheses, the former is in a more delicate position since it has to deal with combining more divergent primary evidence. Concerning the question whether it makes sense to perform an MMRS, it is possible that a researcher intends to perform an MMRS on a certain topic (see Pawson 2008 p. 120: 'method mix' is the new methodological Holy Grail), but that it turns out that a mono-method approach is the only appropriate or feasible way. Ultimately, the research question and the available evidence in the literature remain the key drivers for choosing a mixed methods approach or not. 


\section{References}

Andrew, S., Halcomb, E.J.: Mixed methods research is an effective method of enquiry for community health research. Advances in Contemporary Community and Family Health (2006). doi: 10.5172/conu.2006.23.2.145

Antonacci, D.J., Manuel, C., Davis, E.: Diagnosis and treatment of aggression in individuals with developmental disabilities. Psychiatry Q. (2008). doi: 10.1007/s11126-008-9080-4

Attride-Stirling, J.: Thematic networks: An analytic tool for qualitative research. Qualitative Res. (2001). doi: 10.1177/146879410100100307

Balogh, R., Ouellette-Kuntz, H., Bourne, L., Lunsky, Y., Colantonio, A.: Organising health care services for persons with an intellectual disability. Cochrane Database of Systematic Reviews (2008). doi:

10.1002/14651858.CD007492

Bazeley, P.: Issues in mixing qualitative and quantitative approaches to research. In: Buber, R., Gadner, J.,

Richards, L. (eds.) Applying qualitative methods to marketing management research, pp. 141-156. Palgrave Macmillan, UK (2004)

Borenstein, M., Hedges, L.V., Higgins, J., Rothstein, H.: Introduction to meta-analysis. Wiley, Chichester, UK (2009)

Bouras, N.: Psychiatric and behavioural disorders in developmental disabilities and mental retardation.

Cambridge University Press, Cambridge, UK (1999)

Braun, V., Clarke, V.: Using thematic analysis in psychology. Qualitative Res. in Psychology (2006). doi:10.1191/1478088706qp063oa

Brylewski, J., Duggan, L.: Antipsychotic medication for challenging behaviour in people with intellectual disability: A systematic review of randomized controlled trials. J. of Intellect. Disability Res. (1999). doi: 10.1046/j.1365-2788.1999.043005360.x

Bryman, A.: Integrating quantitative and qualitative research: How is it done? Qualitative Res. (2006). doi: $10.1177 / 1468794106058877$

Bryman, A.: Barriers to integrating quantitative and qualitative research. J. of Mixed Methods Res. (2007). doi: $10.1177 / 2345678906290531$

Chalmers, I., Hedges, L.V., Cooper, H.: A brief history of research synthesis. Evaluation and the Health Professions (2002). doi: 10.1177/0163278702025001003

Chan, S.W.C., Thompson, D.R., Chau, J.P.C., Tam, W.W.S., Chiu, I.W.S., Lo, S.H.S.: The effects of multisensory therapy on behaviour of adult clients with developmental disabilities. A systematic review. International J. of Nurs. Stud. (2010). doi:10.1016/j.ijnurstu.2009.08.004

Collins, K., O'Cathain, A.: Ten points about mixed methods research to be considered by the novice researcher. International J. of Multiple Res. Approaches 3, $2-7$ (2009)

Cooper, H.: Synthesizing research: A guide for literature reviews (3rd ed). Sage, London, UK (1998)

Cooper, H., Hedges, L.V.: The handbook of research synthesis. Russell Sage Foundation, New York (1994)

Creswell, J.W.: Research design: Qualitative, quantitative, and mixed methods approaches (2nd ed.). Sage,

Thousand Oaks, CA (2003)

Creswell, J.W., Plano Clark, V.L.: Designing and conducting mixed methods research. Sage, Thousand Oaks, CA (2007) 
Creswell, J.W., Plano Clark, V.L., Guttmann, M.L., Hanson, E.E.: Advanced mixed methods research design. In: Tashakkori, A., Teddlie, C. (eds.) Handbook of mixed methods in social and behavioral research, pp. 209-240. Sage, Thousand Oaks, CA (2003)

Creswell, J.W., Tashakkori, A.: Developing publishable mixed methods manuscripts. J. of Mixed Methods Res. (2007a). doi: 10.1177/1558689806298644

Creswell, J.W., Tashakkori, A.: Differing perspectives on mixed methods research. J. of Mixed Methods Res. (2007b). doi: 10.1177/1558689807306132

Deb, S., Chaplin, R., Sohanpal, S.K., Unwin, G., Soni, R., Lenotre, L.: The effectiveness of mood stabilizers and antiepileptic medication for the management of behaviour problems in adults with intellectual disability: A systematic review. J. of Intellect. Disability Res. (2008). doi: 10.1111/j.1365-2788.2007.00965.x

Deb, S., Sohanpal, S.K., Soni, R., Lenotre, L., Unwin, G.: The effectiveness of antipsychotic medication in the management of behaviour problems in adults with intellectual disabilities. J. of Intellect. Disability Res. (2007). doi: 10.1111/j.1365-2788.2007.00950.x

Dellinger, A.B., Leech, N.L.: Toward a unified validation framework in mixed methods research. J. of Mixed Methods Res. (2007). doi: 10.1177/1558689807306147

Denscombe, M.: Communities of practice: A research paradigm for the mixed methods approach. J. of Mixed Methods Res. (2008). doi: 10.1177/1558689808316807

Didden, R., Duker, P.C., Korzilius, H.: Meta-analytic study on treatment effectiveness for problem behaviors with individuals who have mental retardation. Am. J. in Ment. Retardation 101, 387-399 (1997)

Didden, R., Korzilius, H., van Oorsouw, W., Sturmey, P.: Behavioral treatment of challenging behaviors in individuals with mild mental retardation: Meta-analysis of single-subject research. Am. J. on Ment. Retardation (2006). doi:10.1352/0895-8017(2006)111[290:BTOCBI]2.0.CO;2

Dixon-Woods, M., Agarwal, S., Jones, D., Young, B., Sutton, A.: Synthesising qualitative and quantitative evidence: A review of possible methods. J. of Health Serv. Res. and Policy 10, 45-53 (2005)

Dixon-Woods, M., Fitzpatrick, R., Roberts, K.: Including qualitative research in systematic reviews: Opportunities and problems. J. of Evaluation in Clinical Practice (2001). doi: 10.1046/j.1365-2753.2001.00257.x Dösen, A., Day, K.: Treating mental illness and behaviour disorders in children and adults with mental retardation. American Psychiatric Publications, Washington, DC (2001)

Doyle, L., Brady, A.-M., Byrne, G.: An overview of mixed methods research. J. of Res. in Nurs. (2009). doi: $10.1177 / 1744987108093962$

Emerson, E.: Challenging behaviour. Analysis and intervention in people with learning difficulties. Cambridge University Press, Cambridge, UK (1995)

Eysenck, H.J.: An exercise in mega-silliness. Am. Psychologist (1978). doi:10.1037/0003-066X.33.5.517.a

Feilzer, M.Y.: Doing mixed methods research pragmatically: Implications for the rediscovery of pragmatism as a research paradigm. J. of Mixed Methods Res. (2010). doi: 10.1177/1558689809349691

Forbes, A., Griffiths, P.: Methodological strategies for the identification and synthesis of 'evidence' to support decision-making in relation to complex health-care systems and practices. Nurs. Inquiry (2002). doi:

10.1046/j.1440-1800.2002.00146.x

Furlan, A.D., Pennick, V., Bombardier, C., Van Tulder, M.: 2009 Updated method guidelines for systematic reviews in the Cochrane Back Review Group. Spine (2009). doi: 10.1097/BRS.0b013e3181b1c99f 
Gelo, O., Braakmann, D., Benetka, G.: Quantitative and qualitative research: Beyond the debate. Integr. Psychological and Behavioral Sci. (2008). doi: 10.1007/s12124-008-9078-3

Greene, J.C.: Toward a methodology of mixed methods social inquiry. Res. in the Schools 13, 93-98 (2006)

Greene, J.C.: Mixed methods in social inquiry. Jossey-Bass, San Francisco, CA (2007)

Greene, J.C.: Is mixed methods social inquiry a distinctive methodology? J. of Mixed Methods Res. (2008). doi: $10.1177 / 1558689807309969$

Greene, J.C., Caracelli, V.J.: Advances in mixed-method evaluation: The challenges and benefits of integrating diverse paradigms. Jossey-Bass, San Francisco, CA (1997)

Greene, J.C., Caracelli, V.J., Graham, W.F.: Toward a conceptual framework for mixed-method evaluation designs. Educational Evaluation and Policy Anal. (1989). doi: 10.3102/01623737011003255

Grey, I.M., Hastings, R.P.: Evidence-based practices in intellectual disability and behaviour disorders. Curr. Opin. in Psychiatry 18, 469-475 (2005)

Gustafsson, C., Ojehagen, A., Hansson, L., Sandlund, M., Nyström, M., Glad, J., et al.: Effects of psychosocial interventions for people with intellectual disabilities and mental health problems. Res. on Soc. Work Pract.

(2009). doi: 10.1177/1049731508329403

Hampton, J.R.: Evidence-based medicine, opinion-based medicine, and real-world medicine. Perspectives in Biol. and Med. (2002). doi: 10.1353/pbm.2002.0070

Hanson, B.: Wither qualitative/quantitative? Grounds for methodological convergence. Quality and Quantity (2008). doi: 10.1007/s11135-006-9041-7

Harden, A., Garcia, J., Oliver, S., Rees, R., Shepherd, J., Brunton, G., et al.: Applying systematic review methods to studies of people's views: An example from public health. J. of Epidemiology and Community Health (2004). doi: 10.1136/jech.2003.014829

Harden, A., Thomas, J.: Methodological issues in combining diverse study types in systematic reviews. International J. of Soc. Res. Methodology (2005). doi: 10.1080/13645570500155078

Harden, A., Thomas, J.: Mixed methods and systematic reviews. In: Tashakkori, A., Teddlie, C. (eds.) Sage handbook of mixed methods in social \& behavioral research (2nd ed.), pp. 749-774. Sage, Thousand Oaks, CA (2010)

Hart, L.C., Smith, S.Z., Swars, S.L., Smith, M.E.: An examination of research methods in mathematics education (1995-2005). J. of Mixed Methods Res. (2009). doi: 10.1177/1558689808325771

Harvey, S.T., Boer, D., Meyer, L.H., Evans, I.M.: Updating a meta-analysis of intervention research with challenging behaviour: Treatment validity and standards of practice. J. of Intellect. \& Developmental Disability (2009). doi:10.1080/13668250802690922

Heyvaert, M., Maes, B., Onghena, P.: A meta-analysis of intervention effects on challenging behaviour among persons with intellectual disabilities. J. of Intellect. Disability Res. (2010). doi: 10.1111/j.1365-

2788.2010.01291.x

Jang, E.E., McDougall, D.E., Pollon, D., Herbert, M., Russell, P.: Integrative mixed methods data analytic strategies in research on school success in challenging circumstances. J. of Mixed Methods Res. (2008). doi: $10.1177 / 1558689808315323$

Jensen, L.A., Allen, M.N.: Meta-synthesis of qualitative findings. Qualitative Health Res. (1996). doi: $10.1177 / 104973239600600407$ 
Johnson, R.B., Onwuegbuzie, A.J.: Mixed methods research: A research paradigm whose time has come. Educational Researcher (2004). doi: 10.3102/0013189X033007014

Johnson, R.B., Onwuegbuzie, A.J., Turner, L.A.: Toward a definition of mixed methods research. J. of Mixed Methods Res. (2007). doi: 10.1177/1558689806298224

Khan, K.S., Riet, G., Popay, J., Nixon, J., Kleijnen, J.: Undertaking systematic reviews of research on effectiveness. Cent. for Reviews and Dissem. Rep. 4, 1-20 (2001)

Kuppens, S., Onghena, P.: Are there enough pieces to unravel the puzzle? A method to determine sufficiency in single-case research synthesis. Paper presented at the Annual Meeting of the American Educational Research Association, Denver, CO (2010)

Lang, R., Koegel, L.K., Ashbaugh, K., Regester, A., Ence, W., Smith, W.: Physical exercise and individuals with autism spectrum disorders: A systematic review. Res. in Autism Spectr. Disorders (2010).

doi:10.1016/j.rasd.2010.01.006

Leech, N.L., Onwuegbuzie, A.J.: A typology of mixed methods research designs. Quality and Quantity (2009). doi: $10.1007 / \mathrm{s} 11135-007-9105-3$

Major, C.H., Savin-Baden, M.: An introduction to qualitative research synthesis: Managing the information explosion in social science research. Routledge, London, UK (2010)

Matson, J.L., Neal, D.: Psychotropic medication use for challenging behaviors in persons with intellectual disabilities: An overview. Res. in Developmental Disabilities (2009). doi:10.1016/j.ridd.2008.08.007

Maxwell, J.: Qualitative research design: An interactive approach (3rd ed.). Sage, Thousand Oaks, CA (2005)

Mays, N., Pope, C., Popay, J.: Systematically reviewing qualitative and quantitative evidence to inform management and policy-making in the health field. J. of Health Services Res. and Policy (2005). doi: $10.1258 / 1355819054308576$

Mays, N., Roberts, E., Popay, J.: Synthesising research evidence. In: Fulop, N., Allen, P., Aileen, C., Black, B. (eds.) Studying the organisation and delivery of health services: Research methods, pp. 188-219. Routledge, London, UK (2001)

McGillivray, J.A., McCabe, M.P.: Emerging trends in the use of drugs to manage the challenging behaviour of people with intellectual disability. J. of Applied Res. in Intellect. Disabilities (2006). doi: 10.1111/j.14683148.2005.00251.x

McKenna, H., Cutliffe, J., McKenna, P.: Evidence-based practice: Demolishing some myths. Nurs. Stand. 14, 39-42 (1999)

Mertens, D.M.: Research and evaluation in education and psychology: Integrating diversity with quantitative, qualitative, and mixed methods (2nd ed.). Sage, Thousand Oaks, CA (2005)

Mertens, D.M.: Transformative paradigm: Mixed methods and social justice. J. of Mixed Methods Res. (2007). doi: $10.1177 / 1558689807302811$

Mertens, D.M.: Divergence and mixed methods. J. of Mixed Methods Res. (2010).

doi:10.1177/1558689809358406

Mitchell, G.J.: Evidence-based practice: Critique and alternative view. Nurs. Sci. Q. 12, 30-35 (1999)

Morgan, D.L.: Practical strategies for combining qualitative and quantitative methods: Applications for health research. Qualitative Health Res. (1998). doi: 10.1177/104973239800800307 
Morgan, D.L.: Paradigms lost and pragmatism regained: Methodological implications of combining qualitative and quantitative methods. J. of Mixed Methods Res. (2007). doi: 10.1177/2345678906292462

Morse, J.M.: Approaches to qualitative-quantitative methodological triangulation. Nurs. Res. 40, 120-123 (1991)

Morse, J.M., Niehaus, L.: Mixed method design: Principles and procedures. Left Coast Press Inc., Walnut Creek, CA (2009)

Newman, I., Benz, C.R.: Qualitative-quantitative research methodology: Exploring the interactive continuum. Southern University of Illinois Press, Carbondale, IL (1998)

Niaz, M.: A rationale for mixed methods (integrative) research programmes in education. J. of Philopsophy of Education (2008). doi: 10.1111/j.1467-9752.2008.00625.x

Niglas, K.: Introducing the qualitative-quantitative continuum: An alternative view of teaching research methods courses. Paper and diagrams presented at the 2006 European Conference on Educational Research, Geneva, Switzerland (2006)

O'Cathain, A., Murphy, E., Nicholl, J.: Integration and publications as indicators of "yield" from mixed methods studies. J. of Mixed Methods Res. (2007). doi: 10.1177/1558689806299094

Oliver, S., Harden, A., Rees, R., Shepherd, J., Brunton, G., Garcia, J., et al.: An emerging framework for integrating different types of evidence in systematic reviews for public health. Evaluation 11, 428-466 (2005)

Onwuegbuzie, A.J., Johnson, R.B.: The validity issue in mixed research. Res. in the Schools 13, 48-63 (2006)

Onwuegbuzie, A.J., Leech, N.L.: Taking the "Q" out of research: Teaching research methodology courses without the divide between quantitative and qualitative paradigms. Quality and Quantity (2005). doi:

$10.1007 / \mathrm{s} 11135-004-1670-0$

Oxman, A.D., Guyatt, G.H.: Guidelines for reading literature reviews. Canadian Med. Association J. 138, 697 703 (1988)

Paterson, B.L., Thorne, B.L., Canam, C., Jillings, C.: Meta-study of qualitative health research. Sage, Thousand Oaks, CA (2001)

Pawson, R.: Method mix, technical hex, and theory fix. In: Bergman, M.M. (ed.) Advances in mixed methods research: Theories and applications, pp. 120-137. Sage, Thousand Oaks, CA (2008)

Pawson, R., Greenhalgh, T., Harvey, G., Walshe, K.: Realist review - A new method of systematic review designed for complex policy interventions. J. of Health Services Res. and Policy (2005).

doi:10.1258/1355819054308530

Plano Clark, V.L., Creswell, J.W., O’Neil Green, D., Shope, R.J.: Mixing quantitative and qualitative approaches: An introduction to emergent mixed methods research. In: Hesse-Biber, S.N., Leavy, P. (eds.) Handbook of emergent methods, pp. 363-387. Guilford Press, New York (2008)

Pluye, P., Gagnon, M.P., Griffiths, F., Johnson-Lafleur, J.: A scoring system for appraising mixed methods research, and concomitantly appraising qualitative, quantitative, and mixed methods primary-level studies in mixed studies reviews. International J. of Nurs. Stud. (2009). doi:10.1016/j.ijnurstu.2009.01.009

Rice, M.J.: Evidence-based practice in psychiatric and mental health nursing: Qualitative meta-synthesis. J. of the Am. Psychiatric Nurses Association (2008). doi: 10.1177/1078390308326661

Risjord, M.W., Dunbar, S.B., Moloney, M.F.: A new foundation for methodological triangulation. J. of Nurs. Scholarsh. (2002). doi: 10.1111/j.1547-5069.2002.00269.x 
Robins, C.S., Ware, N.C., dosReis, S., Willging, C.E., Chung, J.Y., Lewis-Fernandez, R.: Dialogues on mixedmethods and mental health services research: Anticipating challenges, building solutions. Psychiatric Services (2008). doi: 10.1176/appi.ps.59.7.727

Sandelowski, M., Docherty, S., Emden, C.: Qualitative metasynthesis: Issues and techniques. Res. in Nurs. and Health (1997). doi: 10.1002/(SICI)1098-240X(199708)20:4<365::AID-NUR9>3.0.CO;2-E

Sandelowski, M., Voils, C.I., Barroso, J.: Defining and designing mixed research synthesis studies. Res. in the Schools 13, 29-40 (2006)

Sandelowski, M., Voils, C.I., Knaff, G.: On quantitizing. J. of Mixed Methods Res. (2009). doi: $10.1177 / 1558689809334210$

Shogren, K.A., Faggella-Luby, M.N., Bae, S.J., Wehmeyer, M.L.: The effect of choice-making as an intervention for problem behavior: A meta-analysis. J. of Posit. Behav. Interventions (2004). doi:

$10.1177 / 10983007040060040401$

Sohanpal, S.K., Deb, S., Thomas, C., Soni, R., Lenotre, L., Unwin, G.: The effectiveness of antidepressant medication in the management of behaviour problems in adults with intellectual disabilities: A systematic review. J. of Intellect. Disability Res. (2007). doi: 10.1111/j.1365-2788.2006.00935.x

Suri, H., Clarke, D.: Advancements in research synthesis methods: From a methodologically inclusive perspective. Rev. of Educational Res. (2009). doi: 10.3102/0034654308326349

Tashakkori, A., Creswell, J.W.: The new era of mixed methods. J. of Mixed Methods Res. (2007). doi:10.1177/2345678906293042

Tashakkori, A., Teddlie, C.: Mixed methodology: Combining qualitative and quantitative approaches. Sage, Thousand Oaks, CA (1998)

Tashakkori, A., Teddlie, C.: The past and future of mixed methods research: From data triangulation to mixed model designs. In: Tashakkori, A., Teddlie, C. (eds.) Handbook of mixed methods in social and behavioral research, pp. 671-701. Sage, Thousand Oaks, CA (2003a)

Tashakkori, A., Teddlie, C. (Eds.): Handbook of mixed methods in social and behavioural research. Sage, Thousand Oaks, CA (2003b)

Teddlie, C., Tashakkori, A.: A general typology of research designs featuring mixed methods. Res. in the Schools 13, 12-28 (2006)

Thomas, J., Harden, A., Oakley, A., Oliver, S., Sutcliffe, K., Rees, R., et al.: Integrating qualitative research with trials in systematic reviews. British Medical J. (2004). doi: 10.1136/bmj.328.7446.1010

Voils, C.I., Sandelowski, M., Barroso, J., Hasselblad, V.: Making sense of qualitative and quantitative findings in mixed research synthesis studies. Field Methods (2008). doi: 10.1177/1525822X07307463

Walsh, D., Downe, S.: Meta-synthesis method for qualitative research: A literature review. J. of Advanced Nurs. (2005). doi: 10.1111/j.1365-2648.2005.03380.x

Whittemore, R., Knafl, K.: The integrative review: Updated methodology. J. of Advanced Nurs. (2005). doi: 10.1111/j.1365-2648.2005.03621.x

Zimmer, L.: Qualitative meta-synthesis: A question of dialoguing with texts. J. of Advanced Nurs. (2006). doi: 10.1111/j.1365-2648.2006.03721.x 